\title{
Investigation of Professional Competency Level and Training Needs of Field Assistants in Khyber Pakhtunkhwa
}

\section{Asif Nawaz*, Muhammad Zafarullah Khan, Rehmat Ullah, Khalid Nawab and Urooba Pervaiz}

Department of Agricultural Extension Education and Communication, Faculty of Rural Social Sciences, The University of Agriculture, Peshawar, Khyber Pakhtunkhwa, Pakistan.

Abstract | The extension agents have significant contribution in providing effective extension services to the farming community. Therefore, it is vital for administration and management of the extension organizations to investigate competency level of their staff so that training can be provided to them for successful execution of extension tasks. Hence, this study was designed with objective to inspect professional competency level and training needs of Field Assistants of Agriculture Extension Department Khyber Pakhtunkhwa. A sample of 234 respondents was selected and personally interviewed through pre-tested and validated interview schedule. Paired sample t-test and dummy variable regression model were used to achieve study objectives. It was found that Field Assistants were highly competent in conducting farm/home visits followed by conducting meetings and organizing extension campaigns. Highest training needs in professional competency were reported in use of Information and Communication Technologies, use of audio-visual aids and ability of motivating farmers. Regression analysis showed that rural domicile, job experience, and higher educational level of Field Assistants have positive and significant effect on the development of their competency. Therefore, it is suggested to provide in-service training for the Field Assistants in the identified areas for the adequate acquisition of relevant skills and knowledge.

Received | February 01, 2019; Accepted | Jane 12, 2020; Published | August 10, 2020

*Correspondence | Asif Nawaz, Department of Agricultural Extension Education and Communication, Faculty of Rural Social Sciences, The University of Agriculture, Peshawar, Khyber Pakhtunkhwa, Pakistan; Email: asif.nawaz38300@gmail.com

Citation | Nawaz, A., M.Z. Khan, R. Ullah, K. Nawab and U. Pervaiz. 2020. Investigation of professional competency level and training needs of field assistants in Khyber Pakhtunkhwa. Sarhad Journal of Agriculture, 36(3): 867-874.

DOI | http://dx.doi.org/10.17582/journal.sja/2020/36.3.867.874

Keywords | Extension services, Farm/home visits, Interview schedule, Job experience and training needs

\section{Introduction}

A gricultural extension is primarily concerned with improved information exchange among farming community which significantly contributes to the development of agricultural sector (Rehman et al., 2013). The yield of many crops in the country can be increased significantly when the extension agencies provide non-formal education to the farmers about innovative and modern technologies (Rehman et al., 2011). The use of innovative and improved technologies by the farmers will boost their production and eventually will help in poverty reduction (Asfaw et al., 2012) provided that extension services are effective. The effectiveness of extension services relies on extension workers' capabilities that they should be well qualified and aware of their roles so that they can facilitate the farmers who are not capable to use other sources of information (Sail, 2010). In developing countries like Pakistan, the role of extension agents remains vital due to lack of access of the farmers to the other information sources (Okwoche et al., 2009).

Wisconsin Cooperative Extension (2002) viewed professional competency are those knowledge, skills and attitudes which extension workers should possess 
in order to effectively perform their roles as educators. A good educational level of the user and professionalism of agents are the major determinant for success of knowledge exchange system. Competency is directly associated with extension work because the ability of extension workers to achieve set program objectives depends solely on the quality of skills, knowledge and attitude they possess (Swanson, 2006). Field Assistants are central players in providing extension services to the farming community and they are in charge of extension activities at union council level. The Field Assistants make use of a variety of methods and techniques in implementing extension programs and activities. Often, they organize method and result demonstrations, Farmer Field Schools, field days and group meetings (Memon et al. 2013; Ullah et al. 2017).

Therefore, a need was felt to design a study to examine the possessed and required level of competency needed for carrying out successful extension activities because only a competent Field Assistant can persuade farmers to adopt or improve their farming practices. This is due to the fact that Field Assistants are front line soldiers and farmers' interactions are mostly with the Field Assistants of their respective Union Councils and has a greater role in capacity building of the farming community. Keeping in view the importance of these competencies for the Field Assistants, this study was carried out to investigate the professional competencies levels and training needs of the Field Assistants of Khyber Pakhtunkhwa Agriculture Extension Department. The results of this study would serves as input for the policy makers and also for various trainings arranged from time to time for Field Assistants regarding their capacity building.

\section{Materials and Methods}

\section{Study area}

Khyber Pakhtunkhwa province of Pakistan comprised of universe of the study and population of the study comprised of all the Field Assistants staff of provincial Agriculture Extension Department. The province lies at $30^{\circ}$ to $47^{\circ} \mathrm{N}$ latitude and $69^{\circ}$ to $74^{\circ} \mathrm{E}$ longitude with a geographic area of $74,521 \mathrm{Km}^{2}$ sharing $9.36 \%$ of Pakistan total area (GoKP, 2016). Area included in Khyber Pakhtunkhwa province is divided into four agro-ecological zones which are based on temperature, rainfall, climate, altitude and topography in environmental profile of Khyber Pakhtunkhwa. The four agro-ecological zones of Khyber Pakhtunkhwa are northern mountainous zone, eastern mountainous zone, southern piedmont plains and central plain valley (Ahmad, 2012).

\section{Sample selection}

List of all the Field Assistants staff was acquired from provincial Agriculture Extension department. There were 543 Field Assistants offering their services in entire province among which 234 Field Assistants were selected as sample respondents for this study through Sekaran sampling technique (Sekaran, 2006). Proportional allocation sampling technique was used for distribution of sample respondents regarding Agro-Ecological Zone of the province. Thus, 49 Field Assistants were selected from northern mountainous zone, 42 from eastern mountainous zone, 55 from southern piedmont plains and 88 from central plain valley.

\section{Data collection}

Based on study objectives, a well-structured interview schedule was used for collection of primary data from the sample respondents which were personally interviewed at their offices. The interview schedule was pre-tested on 20 Field Assistants prior to data collection in order to accumulate required information. The cronbatch alpha was applied with the help of Statistical Package for Social Sciences (SPSS) that was 0.924 which comes in the range of acceptable internal consistency. The respondents rated each competency statements relative to their perception of the possessed and required level using a five point likert scale by assuming weight of 1 for very low, 2 for low, 3 for medium, 4 for high and 5 for very high. Mean rating values for each competency statement was computed and used to indicate respondents' level of competence. The scheme used to interpret the mean values was $0.00-1.49=$ Very low competency, 1.50-2.49= Low competency, 2.50-3.49= Medium Competency, 3.50-4.49= High competency and 4.50$5.00=$ Very high competency.

\section{Data analysis}

Primary data was analyzed by using Statistical Package for Social Sciences (SPSS) V. 20 and descriptive statistics was utilized for presentation of results along with the following test statistics:

\section{Dummy variable regression model}

According to Gujarati (2003), in regression analysis the dependent variable is frequently influenced not 
only by ratio scale variable but also by variables that indicate the presence or absence of an attribute. Variables that assume such 0 and 1 values are called dummy variables where 1 indicating the presence and 0 indicating absence of that attribute. Dummy variables can be incorporated in regression models just as easily as quantitive variables and such models are called Analysis of Variance (ANOVA) model. Dummy variable regression model was employed to examine the influence of demographic characteristics on the professional competency development of the Field Assistants. The independent variables comprised of demographic characteristics which are used in categorical form (i.e. age, educational level, domicile, farming background, job experience and farming experience of the Field Assistants) and the dependent variable was the Field Assistants' overall mean professional competency of their possessed level which ranges from one to five and the model is defined as:

Mean competency $=\alpha_{0}+\alpha_{1}$ Age $+\alpha_{2}$ Family Back ground $+\alpha_{3}$ Domicile $+\alpha_{4}$ Job Experience $+\alpha_{5}$ Education + $\alpha_{6}$ Farming Experience $+\varepsilon_{i} \quad \ldots(1)$

Where,

$\alpha_{0}=$ Intercept; $\alpha_{1,} \alpha_{2,} \alpha_{3}, \alpha_{4,} \alpha_{5,} \alpha_{6,} \alpha_{7,} \alpha_{8}, \alpha_{9,} \alpha_{10}, \alpha_{11,} \alpha_{12,} \alpha_{13,}$ and $\alpha_{14}$ are slope coefficients; $\varepsilon_{\mathrm{i}}=$ error term.

\section{Paired-sample T-test}

To check the difference between possessed and required level of professional competency of the FAs, paired sample t-test was applied to check the significant difference between the means of the possessed and required levels. The pair t-test for convenience is given as:

$$
t=\frac{\bar{d}}{S d \sqrt{n}}
$$

\section{Where;}

$\mathrm{d}=$ difference between two sample observations (Possessed and Required Level); $n=$ number of pairs; $\mathrm{Sd}=$ standard deviation.

$$
\mathrm{Sd}=\sqrt{\frac{\sum\left(d_{i}-\bar{d}\right)^{2}}{n-1}} \text { and } \bar{d}=\frac{\sum d_{i}}{n}, \text { the meaqn of } d-\text { values }
$$

\section{Results and Discussion}

Required and possessed level of professional competency Results in Table 1 shows that Field Assistants possessed professional competencies with mean value of 3.84 against the required mean value of 4.27. Top most competencies that Field Assistants possessed were reported in conducting farm and home visits with mean value of 4.61 followed by conducting meetings effectively with mean value of 4.55 and required mean of 4.65 and 4.59 respectively on same rank. The third ranked competency at possessed level was organizing extension campaigns with a mean of 4.44 whereas the required mean was 4.51 . Competencies of Field Assistants in conducting method and result demonstrations and organizing field days were at $4^{\text {th }}$ and $5^{\text {th }}$ rank of possessed level with mean value of 4.40 and 4.31 against the required mean value of 4.46 and 4.39 respectively. These results indicated that due to frequent utilization during their job, they possessed these competencies at higher level.

The sixth ranked competency at possessed level was conducting focus group discussion with mean of 4.17 while the required mean was 4.26 . The possessed competency of Field Assistants in identification and prioritization of farmers' needs, usage of principles of teaching and learning and organizing Farmers Field Schools stood at rank $7^{\text {th }}, 8^{\text {th }}$ and $9^{\text {th }}$ with mean value of $3.89,3.86$ and 3.85 against required mean of $4.18,4.47$ and 4.32 respectively. The $10^{\text {th }}$ and $11^{\text {th }}$ ranked possessed competency was understanding group dynamics and facilitation of groups and ability to mobilize local leadership with mean value of 3.71 and 3.70 whereas required mean value were 4.24 and 3.91 respectively. These results revealed that Field Assistants possessed these competencies at medium level because of its less frequent use in their job.

The competencies at possessed level were; writing of field reports $($ mean $=3.67)$ ranked at $12^{\text {th }}$, ability to motivate farmers for adoption of an innovation (mean=3.45) ranked at $13^{\text {th }}$ and manage conflicts (mean=3.29) ranked at $14^{\text {th }}$. The three lowest ranked professional competencies on possessed level were use of audio-visual aids for teaching farmers, ability in reporting (Crop, Weather, crop damage, pest scouting) and use of Information and Communication Technologies for communication with farmers ranked at $15^{\text {th }}, 16^{\text {th }}$ and $17^{\text {th }}$ order with mean of 3.22, 3.21 and 2.93 respectively. It can be concluded from aforementioned results that during the job, Field Assistants could not acquire maximum chance to experience these competencies and thus reported low on possessed scale in comparison to the 
Table 1: Mean, SD and rank of the required and possessed level of professional competencies.

\section{Sr. \# Competencies statements}

1. Conduct farm and home visits effectively

2. Conduct meetings effectively

3. Organize extension campaigns

4. Usage of principles of teaching and learning

5. Conduct method and result demonstration

6. Organize field days

7. Organize Farmer Field Schools

8. Ability to motivate farmers for adoption of an innovation

9. Conduct focus group discussions

10. Understand group dynamics and facilitate groups

11. Identify and prioritize farmers needs

12. Use audio-visual aids for teaching farmers

13. Use of ICTs

14. Write field reports

15. Manage conflicts

16. Ability in reporting (Crop, Hailstorm, Weather, crop damage, pest scouting)

17. Ability to mobilize local leadership

Overall mean
Required level

Mean SD Rank Mean SD Rank

$\begin{array}{llllll}4.65 & 0.58 & 1 & 4.61 & 0.73 & 1\end{array}$

$\begin{array}{llllll}4.59 & 0.60 & 2 & 4.55 & 0.80 & 2\end{array}$

$\begin{array}{llllll}4.51 & 0.63 & 3 & 4.44 & 0.78 & 3\end{array}$

$\begin{array}{llllll}4.47 & 0.88 & 4 & 3.86 & 0.96 & 8\end{array}$

$\begin{array}{llllll}4.46 & 0.80 & 5 & 4.40 & 0.82 & 4\end{array}$

$\begin{array}{llllll}4.39 & 0.78 & 6 & 4.31 & 0.88 & 5\end{array}$

$\begin{array}{llllll}4.32 & 0.85 & 7 & 3.85 & 0.88 & 9\end{array}$

$\begin{array}{llllll}4.29 & 0.95 & 8 & 3.45 & 0.95 & 13\end{array}$

$\begin{array}{llllll}4.26 & 0.77 & 9 & 4.17 & 0.86 & 6\end{array}$

$\begin{array}{llllll}4.24 & 0.91 & 10 & 3.71 & 0.88 & 10\end{array}$

$\begin{array}{llllll}4.18 & 0.85 & 11 & 3.89 & 0.83 & 7\end{array}$

$\begin{array}{llllll}4.15 & 0.83 & 12 & 3.22 & 0.84 & 15\end{array}$

$\begin{array}{llllll}4.08 & 0.92 & 13 & 2.93 & 0.69 & 17\end{array}$

$\begin{array}{llllll}4.06 & 0.93 & 14 & 3.67 & 0.98 & 12\end{array}$

$\begin{array}{llllll}4.02 & 0.93 & 15 & 3.29 & 0.90 & 14\end{array}$

$\begin{array}{llllll}3.97 & 0.93 & 16 & 3.21 & 0.99 & 16\end{array}$

$\begin{array}{llllll}3.91 & 0.91 & 17 & 3.70 & 0.93 & 11\end{array}$

$4.27-3.84$

Source: Field Survey, 2017.

Table 2: Rank order of training needs based on mean required and possessed level of professional competencies.

\section{Sr. Competencies statements}

1. Use of ICTs for communication

2. Use audio-visual aids for teaching farmers

3. Ability to motivate farmers for adoption of an innovation

4. Ability in reporting (Crop, Hailstorm, Weather, pest scouting)

5. Manage conflicts

6. Usage of principles of teaching and learning

7. Understand group dynamics and facilitate groups

8. Organize Farmer Field Schools

9. Write field reports

10. Identify and prioritize farmers needs

11. Ability to mobilize local leadership

12. Conduct focus group discussions

13. Organize field days

14. Organize extension campaigns

15. Conduct method and result demonstration

16. Conduct meetings effectively

17. Conduct farm and home visits

\begin{tabular}{lllll}
$\begin{array}{l}\text { Possessed } \\
\text { level }\end{array}$ & $\begin{array}{l}\text { Required } \\
\text { level }\end{array}$ & \multicolumn{2}{l}{ Training need/ } \\
Mean difference & Rank t-value \\
2.93 & 4.08 & -1.15 & 1 & $-17.83^{* *}$ \\
3.22 & 4.15 & -0.92 & 2 & $-14.01^{* *}$ \\
3.45 & 4.29 & -0.84 & 3 & $-12.50^{* *}$ \\
3.21 & 3.97 & -0.76 & 4 & $-12.07^{* *}$ \\
3.29 & 4.02 & -0.74 & 5 & $-11.64^{* *}$ \\
3.86 & 4.47 & -0.61 & 6 & $-8.39^{* *}$ \\
3.71 & 4.24 & -0.53 & 7 & $-9.27^{* *}$ \\
3.85 & 4.32 & -0.46 & 8 & $-8.52^{* *}$ \\
3.67 & 4.06 & -0.39 & 9 & $-7.98^{* *}$ \\
3.89 & 4.18 & -0.29 & 10 & $-6.73^{* *}$ \\
3.70 & 3.91 & -0.21 & 11 & $-3.55^{* *}$ \\
4.17 & 4.26 & -0.09 & 12 & $-1.80^{\text {NS }}$ \\
4.31 & 4.39 & -0.09 & 13 & $-1.43^{\text {NS }}$ \\
4.44 & 4.51 & -0.07 & 14 & $-1.70^{\text {NS }}$ \\
4.40 & 4.46 & -0.06 & 15 & $-1.26^{\text {NS }}$ \\
4.55 & 4.59 & -0.04 & 16 & $-0.83^{\text {NS }}$ \\
4.61 & 4.65 & -0.04 & 17 & $-0.77^{\text {NS }}$
\end{tabular}

Source: Field Survey, 2017. NS represents Non Significant whereas; " represents significance at 1\% level of probability.

other professional competencies. These results are at par with those of Ashraf et al. (2018) who found that extension field staff has highest competencies in demonstration methods followed by individual contact methods and group contact methods whereas they had medium competencies in Farmer Field Schools, field days and Farm/home visits. 
Training needs in professional competency

Training needs of the Field Assistants based on the mean difference of their possessed and required level presented in Table 2 depicts that top most training need of -1.15 was in the competency of use of ICTs for communication ( $t$-value $=-17.83$ ). Second ranked training needs was reported in competencies of using audio-visual aids for teaching farmers (mean difference $=-0.92, \quad \mathrm{t}$-value $=-14.01$ ) followed by motivating farmers for adoption of an innovation (mean difference $=-0.84, \quad \mathrm{t}$-value $=-12.50) \quad$ and reporting of crops damages, weather and pest scouting data (mean difference $=-0.76$, t-value $=-12.07$ ). Highly significant differences $(\mathrm{P} \leq 0.01)$ were found between the possessed and required level of the above mentioned competencies. These results concludes that due to immense importance of ICT in present days the Field Assistants also felts its need i.e. it's difficult for farming community (Literate) to regularly visit Field Assistant to solve their problems rather they can use ICTs devices to directly contact Field Assistant for their problems.

Training needs in managing conflicts was at $5^{\text {th }}$ rank order with mean difference of -0.74 and t-value of -11.64 . The $6^{\text {th }}$ and $7^{\text {th }}$ ranked training need was reported in competencies regarding usage of principles of teaching and learning and understanding group dynamics and facilitation of groups with mean difference of -0.61 and -0.53 and $t$-values of -8.39 and -9.27 respectively. Organizing Farmer Field Schools stood at $8^{\text {th }}$ position in training need with mean difference of -0.46 and $t$-value $=-8.52$. Highly significant differences $(\mathrm{P} \leq 0.01)$ was found in possessed and required level of competencies in managing conflicts, usage of principles of teaching and learning, understanding group dynamics and facilitation of groups and organizing the Farmer Field Schools. Training needs in competencies of writing field reports, identification and prioritization of farmer needs, and ability to mobilize local leadership stood at $9^{\text {th }}, 10^{\text {th }}$, and $11^{\text {th }}$ order with mean difference of $-0.39,-0.29$ and -0.21 respectively with significant difference $(\mathrm{P} \leq 0.01)$ between their mean of possessed and required level.

Likewise, Field Assistants plays crucial roles in forming and developing well-functioning farmers' groups. During the survey, it was found that the sampled Field Assistants needs trainings regarding characteristics that connote a group, stages of group development and requisite skills to facilitating group formation in order to be competent in understanding group dynamics and facilitating groups. Field Assistants needs to maintain a diary where he notes key tasks and activities completed on a daily basis. Record details such as how many households were visited, who were the people helped and what was the attendance. A report might be written at the end of a month or a quarter. Letting the report go much longer will mean that a lot of details will be lost. In some of the districts like Peshawar, Charsadda and Nowshera, it was found that Field Assistants maintain their diary and also prepare monthly report at the end of a month.

Non-significant differences $(\mathrm{P}>0.05)$ were found in competencies of conducting focus group discussions, organizing field days, extension campaigns, conducting method and result demonstration, farmers' meetings effectively along with farm and home visits. These results revealed that Field Assistants did not require trainings in conducting focus group discussions, organizing field days, organizing extension campaigns, conduction of method and result demonstration, conducting meetings effectively along with conducting farm and home visits because of their frequent occurrence during their job. Similar results were reported by Al-Zahrani et al. (2017) who identified that agricultural extension workers considered ability to motivate farmers to adopt an innovation at $1^{\text {st }}$ rank whereas usage of principles of teaching and learning were at $3^{\text {rd }}$ rank among the training needs. However, the lowest training needs were expressed for ability to mobilize local leadership and in identify farmer's needs and priorities.

Regression analysis of the influence of demographic characteristics on development of professional competency Dummy variable regression model was used to find the effect of demographic characteristics on development of professional competency of the Field Assistants and the results are shown in Table 3 . Results shows that all dummies of the age have positive but statistically non-significant effect on development of the Field Assistants' professional competency. The farming background of the Field Assistants compared to nonfarming had negative but statistically non-significant effect on the development of their professional competency. However, the Field Assistants who belong to rural domicile compared to urban domicile have positive and statistically significant effect on the 
Table 3: Regression analysis of infuence of demographic characteristics on development of professional competency.

$\begin{array}{llll}\text { Independent variables } & \text { Coefficient } & \text { Std. error } & \text { t-ratio } \\ \text { Constant } & 3.413 & 0.090 & 37.943^{* *} \\ \text { Age_D1 } & 0.005 & 0.155 & 0.031 \\ \text { Age_D2 } & 0.001 & 0.170 & 0.008 \\ \text { Age_D3 } & 0.021 & 0.164 & 0.126 \\ \text { Family Background } & -0.337 & 0.253 & -1.331 \\ \text { Domicile } & 0.533 & 0.248 & 2.146^{*} \\ \text { Job experience_D1 } & 0.529 & 0.171 & 3.093^{* *} \\ \text { Job experience_D2 } & 0.699 & 0.229 & 3.050^{* *} \\ \text { Job experience_D3 } & 0.605 & 0.169 & 3.572^{* *} \\ \text { Education_D1 } & -0.132 & 0.095 & -1.387 \\ \text { Education_D2 } & 0.201 & 0.090 & 2.230^{*} \\ \text { Education_D3 } & 0.572 & 0.127 & 4.504^{* *} \\ \text { Farming experience_D1 } & -0.120 & 0.114 & -1.054 \\ \text { Farming experience_D2 } & -0.090 & 0.105 & -0.863 \\ \text { Farming experience_D3 } & -0.041 & 0.109 & -0.375\end{array}$

Age_D1 = 1 if respondent has age b/w 31 to 40 years, 0 otherwise

Age_D2 $=1$ if respondent has age $\mathrm{b} / \mathrm{w} 41$ to 50 years, 0 otherwise

Age_D3 $=1$ if respondent has age of above 50 years, 0 otherwise

Family Background = 1 if the respondent has farming background, 0 otherwise

Domicile $=1$ if the respondent has rural domicile, 0 otherwise

Job experience_D1 = 1 if the respondent has job exp. b/w 6 to 15 years, 0 otherwise

Job experience_D2 $=1$ if the respondent has job exp. b/w 16 to 25 years, 0 otherwise

Job experience_D3 $=1$ if the respondent has job exp. of above 25 years, 0 otherwise

Education_D1 = 1 if the respondent has education of $\mathrm{BQ}+$ Inter, 0 otherwise

Education_D2 $=1$ if the respondent has education of $\mathrm{BQ}+$ Bachelor, 0 otherwise

Education_D3 = 1 if the respondent has education of $\mathrm{BQ}+$ Master, 0 otherwise

Farming experience_D1 $=1$ if respondent has farming exp. b/w 1-10 years, 0 otherwise

Farming experience_D2 $=1$ if respondent has farming exp. b/w 11-20 yrs., 0 otherwise

Farming experience_D3 $=1$ if respondent has farming exp. above 20 years, 0 otherwise

Source: Authors' estimation based on field survey data. " and "indicates significance at 0.05 and 0.01 probability, respectively. $R$-square $=$ 0.365 , Adjusted $R$-square $=0324 ; F$ stat $=8.986^{* * *}$

development of their professional competency. This might be due to the fact that extension activities are concerned with farming and carried out in the rural areas; therefore, Field Assistants with rural domicile had better professional competencies. This might also be due to the fact that the Field Assistants who were living in rural areas had better know how of rural setup and thus effectively performed their jobs and possessed high level of these professional competencies. Similarly, all the dummies of job experience have positive and highly significant effect on the development of their professional competency which could be due to their practical experience on the job which ultimately results in higher professional competencies. The Field Assistants who have education of graduation in addition to basic qualification compared to Field Assistants having basic qualification only have positive and significant effect on the development of their professional competency. Similarly, the Field Assistants who have master education in addition to basic qualification compared to other have positive and highly significant effect on the development of their professional competency that could be attributed to their access to various information sources. All the dummies of farming experience of the Field Assistants have negative but statistically non-significant effect on the development of their professional competency. The $\mathrm{R}$-Square value was 0.365 which indicated that $36.5 \%$ of variation in dependent variable was explained by the independent variables in the model. 
From the present results it can be concluded that Field Assistants possessed those competencies at high level which were of regular nature i.e. farm and home visit, conduct extension meetings, extension campaigns, method and results demonstrations. From the instant results it can also be concluded that these activities were more frequently conducted by them, thus their capacity was build-up to high level and these competencies of Field Assistants were much polished. Moreover, use audio-visual aids for teaching farmers, ability in reporting and use of ICTs were the least possessed competencies by the Field Assistants. It is concluded that due to least occurring nature and poor facilities of ICTs and resources for conducting surveys in order to report regarding hail storm, weather, crop damages, pest scouting the Field Assistants were in lack of these competencies. Therefore, it is suggested that in-service training need to be provided to the Field Assistants in the identified areas for the adequate acquisition of relevant skills and knowledge. Moreover, there is need to include these professional competencies in their curriculum so that they can be capable of performing well in technology dissemination among the farming community.

\section{Novelty Statement}

This study emphasis on professional competency of the field assistants which identified training needs of field assistants so that training could be arranged for them in order to empower them skillfully while conducting extension activities at the field as frontline worker and also will sensitize them to acquire the needed competencies.

\section{Author's Contribution}

Asif Nawaz conceived the idea, collected the data and wrote the manuscript. Muhammad Zafarullah Khan supervised and helped in design of this research study. Rehmat Ullah supported in collection and analysis of primary data and writing results and discussion. Khalid Nawab reviewed and corrected the manuscript for final submission. Urooba Pervaiz helped in write up and incorporation of the corrections suggested by reviewers.

\section{Conflict of interest}

The authors have declared no conflict of interest.
Ahmad, D. 2012. Khyber Pakhtunkhwa state of the environment, Peshawar: Environ. Prot. Agency, GoKP.

Al-Zahrani, K.H., F.O. Aldosari, M.B. Baig, M.Y. Shalaby and G.S. Straquadine. 2017. Assessing the Competencies and Training Needs of Agricultural Extension Workers in Saudi Arabia. J. Agric. Sci. Tech. 19(1): 33-46.

Asfaw, S., B. Shiferaw, F. Simtowe and L. Lipper. 2012. Impact of modern agricultural technologies on smallholder welfare: Evidence from Tanzania and Ethiopia. Food Policy. 37(2): 283-295. https://doi.org/10.1016/j. foodpol.2012.02.013

Ashraf, E., H.K. Sharjeel, R. Babar, M. Junaid, Q. Iqbal, R. Rasheed and N. Fatima. 2018. Perceptions of extension field staff regarding technology transfer through different extension approaches. Sarhad J. Agric. 34(2): 291-300. https://doi.org/10.17582/journal. sja/2018/34.2.291.300

GoKP, 2016. Development statistics of Khyber Pakhtunkhwa. Bureau of statistics, planning and development. Department of Khyber Pakhtunkhwa. pp. 16.

Gujarati, D.N. 2003. Basic econometrics $\left(4^{\text {th }}\right.$ Edition). The McGraw Hill Companies. New York. pp. 297-304.

Memon, R.A., E. Bashir, H.U.R. Mian and A.R. Nasimullah.2013. Extension methods. National Book Foundation, Pakistan. pp. 54-56.

Okwoche, V.A., E.P. Ejembi and C.P.O. Obinne. 2009. A comparative analysis of competencies needed by female and male village agricultural extension agents in benue state, Nigeria. Prod. Agric. Technol. J. (PAT). 5(2): 278-287.

Rehman, F., S. Muhammad,I.Ashraf and S. Hassan. 2011. Factors affecting the effectiveness of print media in the dissemination of agricultural information. Sarhad J. Agric. 27(1): 119-124.

Rehman, F., S. Muhammad, I. Ashraf, K.M. Chaudary, T. Ruby and I. Bibi. 2013. Effect of farmers' socioeconomic characteristics on access to agricultural information: Empirical evidence from Pakistan. J. Anim. Plant Sci. 23(1): 324329.

Sail, R.M. 2010. Empowering of agricultural extensionists: A case study of frontline extensionists of one agricultural extension 
agency.Int.Conf.Agric. Ext.2010(AGREX'10): Empowering of agri-food stakeholders in facing global challenges towards sustainability, 26-28 Oct. 2010, Palm Garden Hotel, IOI Resort Putrajaya, Malaysia. pp. 1166-1199.

Sekaran, U. 2006. Research methods for bussiness. USA, Harnitage Publishing Services. pp. 468.

Swanson, B.J. 2006. Impact of natural and artificial barriers to dispersal on the population structure of bobcats. J. Wild1. Manage. 71(1): 96-102. https://doi.org/10.2193/2005-563
Ullah, R., K. Ullah, I. Ullah, M.Z. Khan and A. Nawaz. 2017. Field assistants impact on agricultural extension activities: A case study of district Dera ismail Khan, Khyber Pakhtunkhwa-Pakistan. Pak. J. Agric. Res. 30(3): 287-293. https://doi.org/10.17582/ journal.pjar/2017.30.3.287.293

Wisconsin Cooperative Extension. 2002. Competencies for extension faculty and academic staff in community based educator roles. Wisconsin: Univ. Wisconsin Publication. pp. 34. 